\title{
(Re)Descobertas e Indefinições - entre a representação, a sub- representação, faroeste e orixás \\ uma breve leitura de Terras do sem fim, de Jorge Amado
}

Auricélio Ferreira de Souza

\section{SciELO Books / SciELO Livros / SciELO Libros}

SOUZA, AF. (Re)Descobertas e Indefinições - entre a representação, a sub-representação, faroeste e orixás: uma breve leitura de Terras do sem fim, de Jorge Amado. In: SWARNAKAR, S., FIGUEIREDO, ELL., and GERMANO, PG., orgs. Nova leitura critica de Jorge Amado [online]. Campina Grande: EDUEPB, 2014, pp. 289-315. ISBN 978-85-7879-328-9. Available from SciELO Books $<\underline{\text { http://books.scielo.org }>\text {. }}$

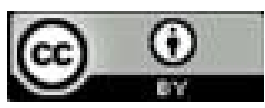

All the contents of this work, except where otherwise noted, is licensed under a Creative Commons Attribution 4.0 International license.

Todo o conteúdo deste trabalho, exceto quando houver ressalva, é publicado sob a licença Creative Commons Atribição 4.0.

Todo el contenido de esta obra, excepto donde se indique lo contrario, está bajo licencia de la licencia $\underline{\text { Creative }}$ Commons Reconocimento 4.0. 


\section{(Re)Descobertas e Indefinições - entre a representação, a sub-representação, faroeste e orixás: uma breve leitura de Terras do sem fim, de Jorge Amado}

Auricélio Ferreira de Souza

\section{Resumo}

Este ensaio propõe uma leitura da obra Terras do sem fim, de Jorge Amado com o intuito de problematizar a questão da representação e da sub-representação social em seus personagens. Intenta-se, a partir de reflexões sobre a Teoria da Representação Social (TRS) sistematizada por Serge Moscovici, associada à crítica de Antônio Candido no que tange a relação literatura e sociedade, discutir o conjunto de implicações que a supervalorização da ideologia do autor traz para a sua escrita, repercutindo em uma compreensão peculiar da história sul baiana, do homem ali subalternizado e do próprio espaço que suporta todos esses.

Palavras-chave: Jorge Amado. Personagem. Representação. Sub-representação. Romance de 30. 


\section{Violência, jagunçagem, amores e sincretismos nas Terras do sem fim}

No fluxo de (re)descobertas e indefinições acerca da própria dimensão de regional propõe-se neste texto um exercício de leitura do romance Terras do Sem-Fim (1942) por acreditar que o mesmo reúne elementos convergentes para a ideia da diversidade representativa que se fortalece na literatura brasileira a partir da década de 30 , inclusive com toda a problemática inerente a esse conceito de diversidade.

Ambientada no Sul da Bahia, a história ocorre no início do século XX e em linhas gerais, trata da luta dos coronéis do cacau pela posse das terras devolutas daquela região. Contudo, os limites da obra se dilatam para muito além disso: o percurso utilizado para contar tal fato passa pela épica nos relatos da chegada dos trabalhadores no desbravamento da Mata de Sequeiro Grande, a colorida tipificação das prostitutas e aventureiros, pela truculência e austeridade dos coronéis, representantes de um interior selvagem e sustentado pela violência da força bruta, chegando a poeticidade de linguagem no trato dos dramas humanos dos explorados e violentados. Sobre essa obra o autor assim se posicionava no prefácio:

Há dez anos passados escrevi um romance, pequeno e violento; sobre o mesmo tema do cacau, ao qual volto hoje. Tinha eu então dezenove anos e iniciava minha vida de romancista. Nesses dez anos escrevi sete roman- 
ces, duas biografias, alguns poemas, centenas de artigos, dezenas de conferências.

Nesses dez anos lutei duramente, viajei, fiz discursos, vivi com meu povo a sua vida. Constato com imensa alegria que uma linha de unidade jamais quebrada liga não só toda a minha obra realizada nesses dez anos como a vida que durante eles vivi: a esperança - mais que esperança, certeza, de que o dia de amanhã será melhor e mais belo.

Em função desse amanhã, cuja madrugada já se levanta sobre a noite da guerra nos campos do este europeu, tenho vivido e escrito.

(AMADO, 1992)

O romance divide-se em seis partes: O Navio é a primeira, e trás o percurso de uma embarcação que parte da cidade da Bahia (atual Salvador), dirigindo-se para o sul, especificamente para Ilhéus, lócus do desbravamento da mata para a expansão do cacau. Nessa parte segue-se um quadro de descrições tanto da paisagem que ladeia o trajeto, de alguns dos protagonistas, bem como de suas expectativas. Comentários dão conta ainda das impressões acerca de outros habitantes 
das terras do sem-fim. Tem-se assim uma espécie de pré-anuncio do diverso painel que se desenvolverá adiante.

A segunda parte intitula-se $A$ Mata e a partir da descrição do temporal em uma mata de contornos assombrosos e gigantescos, principia a narração dos desbravadores avançando palmo a palmo na escuridão da noite na direção do "progresso". A ambientação parece objetivar a criação de efeitos fantasmagóricos que delineiem o impacto da aproximação do mítico, do desconhecido universo ancestral ali existente. Medo e violência marcam esses passos: a força do revólver em punho dá a Juca Badaró o poder de condutor desse empreendimento, que termina por obrigar os capangas supersticiosos a por a ordem na frente do medo. Lançando mão de uma movimentação típica da novela, divide espaço nesta parte, lances narrativos da casa do Coronel Horácio, suas posses, casos notórios vividos na tomada das terras, bem como martírios de sua esposa. Esse painel introdutório das duas famílias rivais - Horácio e Badarós - projeta a mata de Sequeiro Grande como a morada do sincrético: é o espaço onde habitam tanto os valores imemoriais (a natureza bravia e seus recursos quase ilimitados), a ancestralidade negra e cabocla, suas crenças e matrizes culturais, materializada na figura do feiticeiro Jeremias. Mas é também o marco possibilitador da expansão das terras que garantirão a riqueza através de cada nova muda de cacau plantada, ainda que regada por muito sangue.

Gestação de Cidades é a terceira parte, na qual ao longo de dez capítulos é narrado o processo de formação dos 
povoados no entorno da zona cacaueira de Ilhéus. Assim, do incipiente povoado de Tabocas, espécie de depósito de cacau seco, a narrativa conduz a um verdadeiro emaranhado, no qual progressivamente vão se entretocando dramas e histórias envolvendo rameiras, meia dúzia de advogados, dois médicos, escola, hospital, ruas enlameadas e o "fuxico" como demarcação de um modo de sociabilidade provinciano e atrasado. É digno de nota também o tom de extrema oralidade que se fortalece a partir desse ponto. Veja, por exemplo, o próprio início dessa parte quando a repetição da sentença: "Era uma vez três irmãs..." remete as estórias e "causos" do povo, passadas de boca em boca. As sentenças seguintes, num exercício cíclico, dão conta da sina de cada uma dessas três irmãs (Maria, Lúcia, Violeta) possível de ser resignificada em inocência, ascensão, e decadência.

Trapaça, manutenção das aparências, o desenho que começa a se fazer para a traição de Ester, subserviência da igreja, a negativa da escola enquanto espaço de civilidade e outras problemáticas da conturbada vida local, são lentamente tecidas no interior dessa terceira parte que, como a rítmica de um tambor, anuncia a insustentabilidade do clima trágico que se aproxima.

Em O Mar, quarta parte, ganha destaque a figura de capitão João Magalhães, que como único engenheiro (ainda que falso!) passa a ter papel relevante no conflito estabelecido naquela Ihéus: fazer a medição das terras. Essa função é desempenhada não por competência ou consciência do que 
ela implica, mas exclusivamente por ganância, tendo em vista os lucros que a mesma lhe aufeririam. É, portanto, um agente "indireto" ou inconsciente do momento alto do conflito. Acirram-se os relacionamentos: são narradas os rompimentos (Virgílio abandona Margot) as traições (Ester cede a atracão por Virgílio), e até os ainda possíveis "encantamentos líricos " (João Magalhães encanta-se com Don'Ana, que desperta para a primeira paixão). Os clãs rivais atacam-se ainda mais frequentemente. Encaminha-se o clímax do conflito.

Momento em que se constitui de fato o enfrentamento, a quinta parte, $A$ Luta, é o relato de como somam-se brutalidades e tocaias às artimanhas jurídicas nada ortodoxas de Badarós e Horácios na intrincada batalha pela terra. Essa questão, inclusive, repercute por todo o sul da Bahia, dando vulto a uma violência agora irrefreável. Cada lado do conflito se fortalece cada vez mais com jagunços, rifles papa-amarelo, facões e desejo de sangue. O relato segue e culmina com a supremacia de Horácio, que carregará junto com a vitória, um tanto de infelicidade como resultante. O preço do triunfo se incrustará nas memórias, posteriormente relatadas ao narrador.

Espécie de pós-relato, a sexta e última parte, O Progresso, traz o arremate do conflito: quem se assenta no poder após redesenhada a cena. Tabocas cresce, emancipando-se, o que permite a realização de um antigo pleito: mudar o nome para Itabuna. Ilhéus, na esteira das transformações, torna-se bispado. Về-se um Coronel Horácio às voltas com a formação de uma possivel oligarquia: elege, com o poder que tomara para si, deputado

\section{4}


federal (Doutor Jessé) e prefeito (Azevedo), apontando para um novo quadro no cenário político, que na verdade não se apresentam tão novo quanto se possa supor. Mortes à tocaia e a peleja pela terra, são agora lembranças de um passado rememorado. A mata tombara com sua ancestralidade, assim como o feiticeiro Jeremias. Os cacaueiros de agora, multiplicando-se e produzem "frutos estupendos", confirmando a fertilidade daquela terra, adubada com sangue.

Grotesco ou exagerado, como se vê nessas partes, o percurso se operacionaliza é pela tentativa do diverso e do amplo, tanto dos tipos quanto dos ambientes e tônicas que nele se desenrolam.

Isso posto, é possível perceber que esta obra pretende, seguindo o fluxo dos ideais libertários que influenciou a literatura de 30, "ir ao povo", mostrar o homem do interior, seus dilemas, misérias, virtudes e afetos. Era a ideia de um realismo literário como forma viável de não apenas retratar o regional, como nele construir plataforma de denúncia e transformação social:

Não nos pretendíamos modernistas, mas sim modernos: lutávamos por uma literatura brasileira que, sendo brasileira, tivesse um caráter universal; uma literatura inserida no momento histórico em que vivíamos e que se inspirava em nossa realidade, a fim de transformá-la.

(AMADO In RAILLARD, 1992, p. 36) 
Nesse romance, portanto, a mata de Sequeiro Grande, que é desbravada pelos conquistadores, torna-se mais que alvo das disputas entre os coronéis, ela é palco para uma diversidade na representação do homem, do lócus interior e do tempo que Amado tenta compor em seu texto. Assim, também, a família Badaró, cujo patriarca é Sinhô Badaró e a família de Horácio Silveira e sua esposa Éster, são índices possíveis a essa proposta de leitura. Cada uma dessas facções vai agregando ao seu torno outros coronéis, advogados e jagunços que mais do que aliados na guerra por terras, se apresentam como peças nesse vasto painel de diversidade representativa ou sub-representativa. A violência, talvez o principal fio condutor da trama, encontra vastas formas de representação. Ela é factual (tocaias, traições, espancamentos, mortes, expulsões, etc.), veja-se o caso de Firmo, que os Badarós decidem matar em tocaia por ter se negado a vender as terras pelo preço imposto, terras estas que garantiriam acesso natural a Sequeiro Grande e, consequentemente, garantiriam a expansão dos domínios. Mas é também violência simbólica, pois se por um lado os coronéis são postos com contornos bárbaros, de linguagem seca e objetiva, por outro a recorrência a lei ou ao abuso desta - estabelece uma dinâmica nova: o uso da palavra (ainda que sustentado em documentos falsos) num contexto expropriado de civilidade, com o intuito de subalternizar e silenciar o pobre, na figura dos pequenos proprietários. Aliás, a busca de representação do subalternizado é também uma constante nessa obra. Negro Damião, Negro 
Jeremias, Antonio Vitor, Raimunda, a prostituta Margot e até, Ester, que por seu percurso de órfã, romântica, sonhadora, casada à força com Coronel Horácio, é uma sem-voz. Em maior ou menor grau, eles apontam para aqueles que, vivendo numa cena social eminentemente violenta, não têm as condições para seguirem outro percurso senão aquele que as forças hegemônicas lhes apontam dentro deste contexto. Veja-se, por exemplo, o Negro Damião, jagunço do Sinhô Badaró, que, ao tempo em que é um assassino frio, é também um sujeito ingênuo, de gestos tolhidos, sociabilidade ou afetos abafados, não tendo um grande entendimento da extensão de seus atos criminosos e de sua subalternidade no jogo do poder.

Mais do que em outras obras igualmente ligadas a terra e conflitos, como Jubiabá (1935) ou Seara Vermelha (1946), Terras do sem fim agrupa personagens que trazem, a pesar de si e para além de si, uma vocalidade mais aberta - mas não necessariamente polifônica - ou seja, não parecem ser marionetes de forças mais poderosas que eles, como ocorre em Seara Vermetha. Ainda que pressionados ou subalternizados pela violência do contexto, mesmo sucumbindo à "lei do lugar", lei feita na base do fuzil papo-amarelo, o qual garante as terras e avia a morte no mítico interior baiano, nesse romance as personagens são mais "sincréticas" que nos outros, na medida em que possibilitam olhar em vários ângulos a dinâmica daquele conflito.

Mesmo apontando - segundo a crítica - flancos de fragilidade na composição psicológica das personagens, nesta obra é diverso o modo pelo qual tais personas experienciam 
aquilo que o jogo social vai progressivamente lhes impondo. Se não, vejamos: Ester, mulher fina, inteligente e culta, que falava francês, admirava e entendia música, não amando seu marido, Coronel Horácio (ex-tropeiro, que outrora vivenciara a subalternidade, empregado de roça no Rio-do-Braço, enriquecera plantando cacau e se embrutecendo na defesa das posses) vive em sofrimento e nos fornece uma visão de tédio, repulsa e desejo de distanciamento do conflito e de todo seu universo contextual. Ela não é um indivíduo talhado para aquele lócus, fato pelo qual se inquieta e anseia por outro modelo de vida. Doutor Virgílio, Margot e Capitão João Magalhães trazem para a trama a astúcia e perspicácia de um olhar de fora que, lançado sob o embate de forças ali instaurado, busca a possibilidade de lucro sem ceder a qualquer sensibilidade que se possa formar no que diz respeito aos inferiorizados, humilhados e massacrados à margem desse processo. A malandragem por eles enunciada (Virgílio vende "caxixes", documentos falsos; Margot usa o corpo como moeda de ascensão e Capitão João Magalhães vale-se da falsa condição de engenheiro, por meio de um anel de formatura (ganho no jogo de pôquer) não lhes insere, contudo, no grupo hegemônico do poder. $\mathrm{Na}$ verdade, servem a esse grupo e tentam se equilibrar individualmente nessa cena brutalizada. O feiticeiro Jeremias, como ícone organicamente ligado a mata do Sequeiro Grande, ativa uma memória ancestral do negro que vai chocar-se frontalmente com o anúncio do progresso que sub-julga o valor do natural, do anímico, manifesto em sua ação altruísta de ajudar 
aos que estão ao seu redor, curando e aconselhando-os. Diferente de Damião, Jeremias não se deixa subalternizar, mantém resquícios da memória coletiva negra, defende a mata, condena a ação predatória ali estabelecida e morre por conta desse conflito.

Citando apenas estes personagens dentre os vários que compõem a trama, é possível perceber como em termos de disposição das "peças" a estrutura é fortemente voltada para a composição de uma diversidade.

Esse aspecto é exemplificado já no início da obra na construção da cena em que um navio que transporta trabalhadores e coronéis à região cacaueira, fornecendo uma espécie de panorama antecipador dos tipos que atuarão, como protagonistas ou como meras peças, no intrincado jogo pelo poder. No navio estão dispostos os chefes locais na primeira classe, os caixeiros-viajantes, jogadores e prostitutas na segunda, e por fim, trabalhadores migrantes, socialmente silenciados, mas animados pelos sonhos de enriquecimento, amontoados na terceira classe. Essa busca por arquitetar diversidades por vezes não é considerada pelos críticos que, vêm nela mais um painel de colorido exagerado do que uma base de fato polifônica. Para tanto argumentam que, não apenas no romance em questão, mas em grande parte de sua obra, Jorge Amado [...] adotou uma fórmula populista, criando uma imagem de Brasil mulato onde as relações se resolvem por meio da ginga, mas que no fun- 
do mascara todas as contradições da realidade, diz o crítico Alcir Pécora. (PÉCORA)

[...] Mário de Andrade o criticava por ser caudaloso, mas pouco esforçado em seu texto. De uma forma geral, os modernistas entendiam sua obra como um retrocesso, já que não promovia inovações de linguagem e não se abria a várias interpretações.

(ANDRADE)

Ou ainda que Ele retomou o folhetim romântico do século 19. "Mas conseguiu arrastar multidões com isso e criou público para o romance brasileiro", diz Eduardo de Assis Duarte. (BORTOLOTI, 2011, p. 9).

Na obra em questão, se o desejo de Amado foi pelo viés da ficção propor um panorama do que o mandonismo e violência do coronelismo cacaueiro criou no sul baiano, muito disso parece escapar à crítica, para a qual tanto São Jorge dos Ilhéus (1944) quanto Terra dos sem fim (1942) se valem de uma concepção de história claramente "etapista", além de mostrar um efeito de desencaixe entre os personagens e sua função histórica. Mas porque em tão longo período a crítica literária parece estar empenhada em apontar nos romances desse autor mecanismos que desautorizem sua inclusão na categoria de obras relevantes na construção da nova literatura 
brasileira? Estaríamos diante apenas de uma situação de má vontade? De uma interpretação contextual que supervaloriza apenas o fato de sua ampla penetração popular?

Alguns dos pontos apresentados como negativa a essa literatura merecem ser considerados amiúde para que possamos compreender melhor essa recusa. A tentativa de dar ao homem regional contornos universais, é, na visão da crítica, operação que compromete a profundidade psicológica das personagens, posto que a ideologia política de Amado é, ela própria, já comprometida com uma ideia de "universal" fortemente ligada aos preceitos socialistas/comunistas. A dedicatória à Dmitri Shostakovich, compositor e soldado de Leningrado em Terra dos sem fim, seria um claro indicador dessa ligação.

A frase inicial: $O$ apito do navio era como um lamento $e$ corton o crepúsculo que cobria a cidade e o trecho que a segue, no qual é descrito a chegada do navio (símbolo do progresso e da transformação) na cidade interiorana - de "casario de construção antiga" com seus "telhados negros, ruas calçadas de pedras enormes" por onde não passava ninguém - (portanto, símbolo do atraso e de um modelo de sociabilidade opressor e asfixiante) igualmente pode ser utilizado para argumentar quanto ao endereçamento da ideia de interior oprimido e metrópole opressora.

Em oposição a essa interpretação da crítica, escritores, artistas e intelectuais que defendem a obra de Amado afirmam que sua grande criatividade na composição do vasto 
elenco de tipos, muitos incorporados ao imaginário brasileiro, sobretudo baiano, resulta da sua capacidade de escuta do repertório das estórias orais desse povo, conferindo-lhe vasta penetração popular e que tal fenômeno, portanto, "libera" sua obra da profundidade psicológica que a crítica espera no romance de 30. O livro pode ter densidade psicológica e ser um péssimo romance. Jorge Amado permitiu que muitos leitores gostassem de literatura e se reconciliassem com os temas nacionais, diz o escritor João Ubaldo Ribeiro (In BORTOLOTI, op.cit., p.9). O argumento seria, portanto, o de que o apelo popular ocorre porque há identificação com o povo, que não apenas se vê representado nessa obra, como aprova tal representação, fator que se reflete na alta e constante vendagem dos títulos do autor, amplamente reeditado e traduzido.

Contudo, para confrontar tal argumento é preciso lembrar que tratar recorrentemente o povo e suas temáticas, não necessariamente significa representar esse povo no que tange a não apenas "pintá-lo", mas fazer com que sua voz (antes conflituosa que uníssona) encontre mecanismos de fluxo no eixo da literatura proposta, afinal as teorizações acerca da representação via arte, apontam para uma problemática mais profunda do que a mera expressão sucitadora do interesse "turístico" pelo pitoresco do(no) regional.

Arruda (2002), pensado as bases da Teoria das Representações a partir da obra fundante $A$ Psicanálise, sua imagem e seu público, de 1961 na qual Serge Moscovici busca, por meio das contribuições da sociologia de Durkheim, sistemati- 
zar na psicologia social uma teorização sobre a representação social, nos ajuda a perceber o peso que o representar ou o sub-representar exerce na obra artística. Certamente tal peso é que se constituirá como elemento diferenciador em termos de diversidade na literatura feita no Brasil antes e depois de 30, como já vimos, década esta extremamente convulsiva no cenário nacional.

Sobre as contribuições dessa teoria, assim se posiciona Arruda (2002, p.129):

A Teoria das Representações Sociais (TRS) operacionalizava um conceito para trabalhar com o pensamento social em sua dinâmica e em sua diversidade. Partia da premissa de que existem formas diferentes de conhecer e de se comunicar, guiadas por objetivos diferentes, formas que são móveis, e define duas delas, pregnantes nas nossas sociedades: a consensual e a científica, cada uma gerando seu próprio universo. A diferença, no caso, não significa hierarquia nem isolamento entre elas, apenas propósitos diversos. O universo consensual seria aquele que se constitui principalmente na conversação informal, na 
vida cotidiana, enquanto o universo reificado se cristaliza no espaço científico, com seus cânones de linguagem e sua hierarquia interna. Ambas, portanto, apesar de terem propósitos diferentes, são eficazes e indispensáveis para a vida humana. As representações sociais constroem-se mais freqüentemente na esfera consensual, embora as duas esferas não sejam totalmente estanques. (grifos do autor).

Desse quadro depreende-se que

[...] no universo consensual aparentemente não há fronteiras, todos podem falar de tudo, enquanto no retificado só falam os especialistas. De acordo com ele, seríamos todos "sábios amadores", capazes de opinar sobre qualquer assunto numa mesa de bar, diferentemente do que ocorre nos meios científicos, nos quais a especialidade determina quem pode falar sobre o quê. Arruda.

(ARRUDA, p.130) 
Isso posto, pensando o romance em questão, podemos dizer que tanto há a representação consensual, na medida em que o canônico cede ao popular (o homem interiorano, sua geografia, história, linguagem, costumes e agruras) quanto, dentro desse, um certo exagero que tende a sub-representação, entendendo esse termo como o fenômeno pelo qual um elemento é posto na representação, mas não operacionaliza a função que dele se espera. Seria um ícone impotente de sua mais primordial condição: possibilitar uma fixação ideológica. As razões para a incidência deste fato na obra em questão, devese, talvez, como já afirmara Candido (op.cit. 2006, p.131), por certa "preponderância do problema sobre o personagem." A necessidade de trazer um fato esquecido ou perdido - no caso, a história do sul baiano - por meio de uma mnemônica ficcional parece, nesse caso, ser posto em maior valorização em detrimento aos personagens que operacionalizarão tal ação, o que lhes confere uma rasa psicologia e, como consequência disso, um silenciamento de sua potência icônica.

Numa perspectiva semelhante, Moscovici (2007, p.58) nos lembra que:

As representações que nós fabricamos duma teoria científica, de uma nação, de um objeto, etc. - são sempre o resultado de um esforço constante de tornar real algo que é incomum (não-familiar), ou que nos dá um sentimento de não-familiaridade. E através delas nós superamos o problema e o inte- 
gramos em nosso mundo mental e físico, que é, com isso, enriquecido e transformado. Depois de uma série de ajustamentos, o que estava longe, parece ao alcance de nossa mão; o que era abstrato torna-se concreto e quase normal $[\ldots]$ as imagens e ideias com as quais nós compreendemos o não-usual apenas trazem-nos de volta ao que nós já conhecíamos e com o qual já estávamos familiarizados.

(MOSCOVICI, 2007, p.58)

Diante disso, em Amado, e em particular no romance em questão, é possível que a nítida influência que os ideais comunistas de luta contra as injustiças, garantia coletiva de direitos, dentre esses a questão da terra e de modelos produtivos sustentáveis nela empreendidos, tenham sido transpostos para o romance, alterando consideravelmente as principais matizes do contexto cacaueiro, a saber: o homem, o lócus de sua vivência e, consequentemente, os mecanismos pelos quais ambos se entre - tocam e se transformam. O desejo, pois, de um homem universal, imerso numa contextualidade igualmente universal: a da exploração que precisa ser combatida a todo custo, como "[...] madrugada que já se levanta sobre a noite da guerra nos campos do este europeu [...]" para usar as próprias palavras do autor, contidas no prefácio da obra em tela, termina por, inversamente, resultar num homem, numa 
terra e num embate, muito mais alinhado com o ideário que o autor esperava, do que com a densidade efetivamente representante da sociedade que suporta a trama.

Sobre esse aspecto, em oportunidade na qual se referia a problemática na literatura de Jorge Amado, Antonio Cândido afirma: "nesses romances há um intuito ideológico ostensivo demais, que, por não ser incorporado como elemento necessário à composição, parece com frequência superposição indigerida" $"$.

\section{O feiticeiro Jeremias, a catarse da raça}

Já vai adiantada certa vertente da análise e da crítica literária que tem procurado voltar-se para personagens ditas "secundárias" defendendo que, perquiridas com o instrumental adequado, revelam novas e profundas dimensões do texto. Ocupando geralmente uma posição de subalternidade, essas personagens ao passo que silenciadas e negligenciadas pelo plano da ação central, podem, por isso mesmo, estar impregnadas de possibilidades em aberto, no que tange a pontos de vista plurivalentes tanto dessa ação quanto, e, inclusive, do plano de sua criação. Funcionam como testemunhas comportadas, mas potentes em linguagem, posto que, não tendo lugar de destaque na cena (o centro do palco), lhes sobra a tangente

1 In Enciclopédia On-Line de Literatura Brasileira do Itaú Cultural. Verbete Amado, Jorge (1912 - 2001). Disponível em: http:/ / www.itaucultural. org.br/aplicexternas/enciclopedia_lit/index.cfm?fuseaction=biografias_ texto\&cd_verbete=12265\&cd_item=226 Acesso: 09/10/2012. 
de todos os outros ângulos.

Considerando essa perspectiva, a partir desse ponto do texto propõe-se um exercício de leitura sobre a personagem Jeremias, de Terra do sem fim. O intuito é investigar como pesando sobre ele caracteres como a negritude, a velhice, o isolamento e o resguardo da tradição ancestral, este compreende o jogo de poder que se estreita no entorno de Sequeiro Grande e, como se posiciona a partir de tal compreensão.

Se formos contabilizar veremos que o feiticeiro Jeremias não tem uma numerosa aparição na obra, e que, somado ao fato de ser negro, pobre e velho, não tendo, portanto voz de mando no conflito, tão pouco interessando aos coronéis como força de combate, o torna "secundário" na trama. Contudo, a ideia central que resume o conflito entre Badarós e Horácios: a terra adubada com sangue é plenamente compreendida por ele no seu momento clímax, mesmo em face da precariedade de seu modus operandi.

Jeremias se ergue. Desta vez não precisou de bordão para sustentar em pé seu corpo centenário. Deu dois passos para a porta da cabana. Agora seus olhos quase cegos viam perfeitamente vista a mata em todo seu esplendor. E a via desde os dias mais longínquos do passado até esta noite que marcava o seu fim.

(AMADO, 1970, p.123) 
Mais que isso, a cena em que se dá a "praga ardente" por ele lançada sobre os invasores da mata, evidencia que o mesmo, ainda que silenciado, tem uma ativa consciência do processo predatório que se anuncia como irreversível.

[...] Sabia que os homens a iam penetrar, iam derrubar a floresta, matar os animais, plantar cacau na terra onde havia sido a mata de Sequeiro Grande. Enxergou o fogo das queimadas se estorcendo nos cipós, lambendo os troncos, ouviu o miado das onças acossadas, o guincho dos macacos, o silvo das cobras se queimando. Viu os homens de machado e facões acabando com o resto que o fogo deixara, pelando tudo, pondo a terra nua, arrancando até as raízes mais profundas dos troncos.

(Ibid., p.123-124)

Talvez essa consciência seja a mais acessa de todos os envolvidos, ao ponto de que, justamente por isso, se converta numa verbalização tão arrebatadora, impossível de ser vertida por outra personagem. A palavra de Jeremias queima antes que o fogo factual chegue à mata.

As palavras de Jeremias eram para os 
seus deuses, os deuses que tinham vindo das florestas da África, Ogum, Oxossi, Iansã, Oxolufã, Omolu, e também a Exu, que é o diabo. Clamava por eles para que desencadeassem a sua cólera sobre aqueles que iam perturbar a paz da sua moradia.

(Ibid., p.124)

É ele, Jeremias, a ancestralidade até então amordaçada e posta fora do ângulo central, que vocifera agora a memória acesa em palavra contra os que, já avançando naquele anímico espaço, sedentos pelo poder, conhecerão a fatídica sina dos gananciosos: ser soterrados pelos escombros de sua própria barbárie. E, por fim, sua cólera verte-se em um fluxo:

- O olho da piedade secou e eles tá olhando pra mata com o olho da ruindade.[...] Agora eles vai entrar na mata mas antes vai morrer homem e mulher, os menino e até os bicho de pena. Vai morrer até não ter mais buraco onde enterrar, até os urubu não dar mais abasto de tanta carniça, até a terra tá vermelha de sangue que vire rio nas estrada e nele se afogue os parente, os vizinho e as amizade deles, sem faltar nenhum. Vão entrar 
na mata mas é pisando carne de gente, pisando defunto. Cada pé de pau que eles derrube vai ser um homem derrubado, e os urubu vai ser tanto que vai esconder o sol. Carne vai ser estrume de pé de cacau, cada muda vai ser regada com sangue deles, deles tudo, tudo, sem faltar nenhum.

(Ibid., p.124)

O cacau é o começo, mas também é anunciado pelo feiticeiro como sendo o fim: - Cada filho vai plantar seu cacaneiro em riba do sangue do pai (...)

Jeremias, tendo consciência de que seu fim antecipa o da mata, e de que a organicidade com a aquela natureza rompera-se, leva a exaustão o seu fluxo como se a palavra esvaziasse de seu corpo longevo e gasto, o último sopro anímico. "[...] Seu corpo foi cedendo, tinha sido imenso o esforço. Foi cedendo, seus olhos cegaram de todo, as pernas se dobraram e ele caiu sobre a terra, os pés tocaram no negro Damião transido de medo." (AMADO, 1970, p.124).

Esse rompimento já não deixa dúvida: o feiticeiro cumprira sua potência de linguagem, dissera-se, literalmente, até o auto-aniquilamento, compreendendo que seu sentido prendia-se organicamente ao sentido da mata de Sequeiro Grande. Se quanto ao futuro nada pode fazer, posto que velho e inapto ao combate, quanto ao presente ele se cumpre: realiza a catarse 
possível ao negro criado nos limites da obra em questão.

\section{Conclusão}

Corroborando a tese de Lukács de que "a vida faz-se criação literária", e pelo que o romance agregou ao curso de seu desenvolvimento, espera-se que este possibilite, por meio de exercício da leitura, "[...] descobrir e construir, pela forma, a totalidade oculta da vida" (LUKÁCS 2009, p.60). Totalidade esta, que em face das novas demandas e configurações da experiência humana, necessita obrigatoriamente promover o caráter aberto, polifônico desse homem e de seus modus de experienciar, seja a construção ou a destruição, o amor ou a dor, os afetos e suas diferentes matizes, já que se esclerosara a epopéia e sua totalidade fechada. De tal modo, essa compreensão só pode advir da proficiente arregimantação de certos ativadores da tessitura vida x criação literária, em especial entre estes, acreditamos estar o processo de representação do lócus, do evento e, principalmente, das personas criadas para dar sustento às ações que edificarão a obra pretendida.

Assim, acreditamos que só há de fato obra se a proposta lançada alude, ou mais: ativa, uma experiência identificável no plano da vida sócio-históricamente reconhecível pelos receptores de tal proposta. Equivale dizer que a "totalidade oculta da vida” de que nos fala Lukács, não pode ocorrer se não por esta representação, posto que segundo o pensamento lukácsiano “[...] o homem torna-se ao mesmo tempo o escritor de sua própria vida e o observador dessa vida como uma obra de arte criada". 
Nessa duplicidade em que se coloca em relação à obra literária, tanto autor, quanto receptores, sabem que a personagem não é ícone de si, imagem "turística" autoreferenciada, mas eco de muitos sentidos possíveis, ou ainda em vias de tessitura na obra e para além dela, pois convertem-se em perpétua busca, conforme nos lembra Lukács:

[...] a busca é apenas a expressão, da perspectiva do sujeito, de que tanto a totalidade objetiva da vida quanto sua relação com os sujeitos nada têm em si de espontanemente harmonioso - aponta para a intenção da configuração: todos os abismos e fissuras inerentes à situação histórica têm de ser incorporados à configuração e não podem nem devem ser encobertos por meios composicionais. Assim, a intenção fundamental determinante da forma do romance objetiva-se como psicologia dos heróis romanescos: eles buscam algo. (os grifos são meus)

(LUKÁCS 2009, p.60)

Nesse trabalho, em que propusemos um breve exercício de leitura sobre o romance de Jorge Amado, pensamos que essa problematização quanto a certos procedimentos ou meios 
composicionais largamente utilizados pelo autor, como a "alegorização" — no sentido carnavalesco do termo — , das personagens em detrimento ao processo de representação social, gera profícuos pontos de reflexão sobre o já acalorado debate em torno do conjunto da obra de Amado. Tais pontos, contudo, a nosso ver, não devem ser encaminhados na direção de auferir ou subtrair qualidade artística ao texto, mas sim na de fortalecer a instrumentalização das análises e da crítica acerca do que esses processos têm a nos revelar sobre o romance brasileiro de 30 e, em especial, sobre as formas de subalternização que o mesmo pioneiramente discutiu e que podem ser (re) descobertas ou (re) definidas a partir de um olhar mais atencioso para as chamadas personagens secundárias.

\section{Referências}

AMADO. Terras do sem fim. 27. ed. São Paulo: Martins, 1970.

In RAILLARD, Alice. Conversando com

Jorge Amado. Rio de Janeiro: Record, 1992, p.36.

ARRUDA, Ângela. Teoria das representações sociais e Teorias de gênero In Cadernos de Pesquisa, n. 117, p 127-147 nov. 2002. Universidade Federal do Rio de Janeiro.

BORTOLOTI, Marcelo. Primeira obra de Jorge Amado 
completa 80 anos. São Paulo: Folha de São Paulo, 9 abr. 2011.

BOSI, Alfredo. História concisa da literatura brasileira. 39. ed. São Paulo: Cultrix, 1994.

CANDIDO, Antônio. Literatura e Sociedade. Rio de Janeiro: Ouro sobre azul, 2006.

LUKÁCS, G. A teoria do romance: um ensaio histórico-filosófico sobre as formas da grande épica. 2.ed. São Paulo: Duas Cidades; Editora 34, 2009.

MOSCOVICI, S. Representações sociais: investigações em psicologia social. Rio de Janeiro: Vozes, 2003. 